\title{
9. Education and justice: inclusion, exclusion and belonging
}

\author{
Başak Akkan and Ayşe Buğra
}

\subsection{INTRODUCTION}

This chapter investigates the dynamics of inclusion and exclusion affecting minorities and other vulnerable groups in the system of education as an area where the manifestation of the three dimensions of justice pertaining to redistribution, recognition and representation has been traced in six country cases: Austria, Hungary, the Netherlands, Portugal, Turkey and the UK. This investigation is carried out by exploring the discourses on education situated within the political frames in which the dynamics of inclusion and exclusion affecting minorities and vulnerable groups are constructed. The determinants of inclusive education include access to good quality education and freedom to choose the education that complies with the cultural preferences and the understanding of good life of different groups of people. The chapter discusses the tensions pertaining to the inclusionary and exclusionary aspects of education with respect to the recognitive and representative factors that define the terms of belonging in a pluralistic society.

The chapter furthermore argues that the life chances of students from minority groups are determined by the sense of belonging in an inclusionary education system. The exclusionary dynamics created by the inequalities of opportunity in access to quality education and the experiences of alienation/ discrimination caused by misrecognition which affect school performance limit the contribution education is expected to make to capability development for children from minority groups. The inclusionary features of a system of education, which recognizes differences of social and cultural background and values the parental choice, have implications for the development of the capabilities of children. However, the parents' freedom in choosing the type of education which they find in conformity with the values underlying their conception of good life might not always be in conformity with the children's freedom to choose and affects their future life chances. Then, how do the demands and choices of parents from minority groups relate to the well-being 
and capabilities of their children? In this regard, the chapter argues that an inclusionary system of education lies at the heart of such a vision where the individuals, with their unburdened distinctiveness, could live the good lives that they choose through their enhanced capabilities, or substantive freedoms, in the education system.

Within this analytical frame, the transformative character of education is highlighted in an inquiry into the ways in which the tensions between equality and difference or between different definitions of good life and the development of a sense of belonging in society emerge in the systems of education of different country cases.

\subsection{THEORETICAL FRAMEWORK}

Fraser's normative theory of justice (Fraser 2003, 2008) highlights that socio-economic disadvantages are significantly intertwined with cultural differences and calls for the assessment of different dimensions of injustice related to redistribution and recognition (see Chapters 1 and 4). Her tripartite justice framework has been employed by education scholars to understand education as a matter of justice (Gewirtz 2006; Huttunen 2007; Keddie 2012a, 2012b; Power 2012). The literature suggests that education with its inclusionary and exclusionary boundaries, on the one hand, reinforces existing social inequalities pertaining to class, gender, race and ethnicity (Hart 2012); on the other hand, education has a role in overcoming injustices and eradicating persistent inequalities in society (Unterhalter 2003; Tikly and Barrett 2011; Power 2012).

The redistributive dimension of justice becomes significant given the socio-economically driven inequalities in access to good quality education. Poverty is still considered to be one of the causes as well as the consequence of educational inequalities leading to early school leaving and affecting the labour market prospects of children from a disadvantaged background (Keddie $2012 b)$. Although the socio-economic disadvantages, which also have a spatial character, significantly define equal access to education, the injustices in education are not limited to the class positions. Ethnic, racial, cultural or religious backgrounds could also operate as important categories of exclusion and hamper students' educational outcomes (Keddie 2012b).

Injustices faced by minority groups are often defined by the interface between the misrecognition of ethnic, religious or racial differences and redistributive inequalities. The exclusionary dynamics created by the inequalities of opportunity in access to quality education as well as the experiences of alienation caused by misrecognition which affect school performance limit the contribution education is expected to make to capability development for children from minority groups. Hence, differences themselves are not matters 
of inequality, but, depending on 'the extent to which race, ethnic, or gender differences are salient with regard to the experience of education' (Walker and Unterhalter 2007, p. 10), the social arrangements in the school environment can appear as inequality producing mechanisms. Injustices in the realm of education might stem from rules and practices with an exclusionary character that are insensitive and culturally blind to the diverse backgrounds of students; or differences could be overemphasized in a discriminatory and stigmatizing manner. These could manifest themselves in the silencing of knowledge of the 'other' in the curriculum, or creating inferiority in relation to the dominant culture of the society as a result of the prevailing middle-class values in the education system (Keddie 2012b; see also Lynch and Baker 2005). The ways in which cultural, ethnic, linguistic, religious, racial and other diversities are addressed in a system of education define the inclusiveness of the education system which could foster either belonging or alienation among students from minority communities.

Discursive space of education manifests the normative understanding of a shared future of the society and the ways and means of dealing with different value systems in the social context. In today's pluralistic societies where conflicting values coexist, the moral values and societal norms that the education system incorporates and promotes become especially important in their implications for social cohesion. Several critical questions emerge here: In a particular context, could the education system accommodate the plurality of 'good lives' associated with different cultural and religious belief systems? Whose and what knowledge are privileged in an education system? The extent to which inclusiveness characterizes the rules, practices and content of education in these areas appears as the main question to be pursued in contemplating the discursive frame of education where concerns of 'equality and difference' are revealed in a given society.

Education has a crucial significance for the formation of common values and a shared language as the basis of societal dialogue around the notions of the common good. The socio-economic inequalities and cultural differences that are not well accommodated in an education system are perpetuated by the non-representation of the minority cultures and vulnerable groups in the society. Either they are not represented well, that is to say, their claims do not find a voice in the education system, or their membership to a certain group is highlighted and their claims are expected to voice those of the group with which they are identified. Keddie (2012b, p. 275) refers to this matter as 'unburdening minority groups of their constructed distinctiveness [which might go together with stigma]'. ${ }^{1}$

Respecting parental choice is a way to address the question of representation in the education system. Parental choice is granted by the human rights legal framework as the Universal Declaration of Human Rights (1948) states in 
Article 26: 'Parents have a prior right to choose the kind of education that shall be given to their children.' 2 And the right to choose the kind of education as it is being framed by the international law pertains to the religious freedom of the parents. Right to education is a complex legal issue; it belongs both to freedom rights and social, cultural and economic rights (Salát 2019). Parental choice as it is being discussed in this chapter pertains to the choice of the education system that best suits the cultural and religious sensitivities of the family. The overemphasis on the choice paradigm is also a contested one, as our choices could also be adapted preferences determined by the boundaries of society and policies (Nussbaum 2000). In a different vein, the emphasis on parental choice could controversially help the privileged class to extend the educational opportunities for their children. The principles for fair representation and equal opportunities manifest tensions in contemporary societies. Thus, a further question is the possible tension between parental choice and future choices that would be available to children. Parental choice in certain cases could be in conflict with the life chances of children.

In this respect, the capability approach provides significant insights into dealing with such difficult questions pertaining to the place of education for a just society. According to Sen, education is 'a relatively small number of centrally important beings and doings that are crucial to well-being' (Sen 1992, p. 44). Hence, discourses on the well-being of children in relation to their capability building experiences in the education system open the way to dealing with the question of equality and difference with a perspective that avoids 'binary thinking' (Lister 2003).

In Sen's capability approach, capability refers to the substantive freedom to achieve actual functionings, or various things a person may value doing or being (Sen 1999). Here Sen draws attention to personal differences, diversities in the physical environment, variations in social climate, which determine the different opportunities to translate resources into the desired functioning to achieve alternative lifestyles. He also insists on the relational aspect of capability deprivation and argues that the social exclusion paradigm makes a useful contribution to the capability approach by highlighting this aspect (Sen 2009). In Sen's approach, therefore, freedom acquires a different meaning than it has in the conceptualizations of justice that exclusively consider the resources available to people to pursue their valued ends, and it takes into account the differences in the ability to use these resources which contribute to the general capability of a person to live more freely. This approach addresses political freedoms, economic facilities, social opportunities, transparency guarantees and protective security which complement each other in ways that determine the strength of their joint significance for freedom as an end (Sen 1999).

The consideration of capabilities rather than resources draws attention to certain conditions that define individuals' decisions and choices; hence, the 
capability approach takes into consideration 'human diversity; complex social relations; a sense of reciprocity between people; appreciation that people can reflect reasonably on what they value for themselves and others; and a concern to equalize, not opportunities or outcomes, but rather capabilities' (Walker and Unterhalter 2007, p. 3) that allow individuals to take decisions, make choices that matter to them for a 'valuable life' (Walker and Unterhalter 2007). What, then, are the capabilities which matter most in developing agency and autonomy for educational opportunities and life choices (Walker 2006)?

The capability approach perceives education as an 'unqualified good for human development freedom' (Walker 2006, p. 168). The normative ideal of education as the prerequisite to the development of basic capabilities needs to be distinguished from the non-ideal reality of education which could well be a space of 'unfreedom' and capability deprivation that reproduces inequalities (Unterhalter 2003; Walker 2006; Tikly and Barrett 2011). Education, in its importance for the well-being of children, is to be constructed as a place of freedom in the sense that it is expected to be a transformative and empowering experience that would affect our present and future choices. Walker and Unterhalter highlight this point and argue that: 'We need to be clear that respecting a plurality of conceptions of the good life (and hence of how education is arranged) is not the same as endorsing all versions of the good life, and this has clear educational implications' (Walker and Unterhalter 2007, p. 15).

Education in this respect lies at the heart of such a vision of convergence where the individuals with their unburdened distinctiveness could purse the valuable lives that they define through their enhanced capabilities and freedom in the education system. This is a transformative process where the redistributive, recognitive and representative ideals in the education system contribute to the development of a sense of belonging in society. The freedom to pursue individual choices goes hand in hand with this sense of belonging as education, with its transformative character, could accommodate equality and diversity as complementary ideals in our complex societies.

\subsection{METHODOLOGY}

As argued by Tikly and Barrett (2011), the institutional injustices are embedded in the discourses which shape our understandings of education by indicating what is/is not or what can/cannot be said. Therefore, the discourses on education are important to understand the political frame in which inequalities are constructed. The methodology of this chapter includes qualitative content analysis with elements of discourse analysis. Such methodological approach involves a systematic search for underlying meanings, patterns and processes and careful mapping of themes and arguments used to convey the exclusionary/inclusionary aspects of education. The investigations of different country 
cases conducted for this chapter in the context of ETHOS share the common methodological approach which consists of the analysis of official documents and reports by non-governmental organizations (NGOs) active in the field of education or concerned with minority issues in general, as well as a series of interviews with administrators, politicians, teachers and NGO representatives. Documents analysed in each country context are in the political or advocacy category such as policy documents and strategy papers by the Ministry of Education, NGO reports, other governmental reports, recommendation papers, laws, local regulation and so on. Along with the document analysis, interviews were conducted with the representatives of teachers' unions, student unions, advocacy groups engaged in the area of education, representatives of minority groups, administrators from the Ministry of Education and other relevant ministries. The country case studies (Akkan and Ruben 2018; Dupont 2018; Hiah 2018; Kende 2018; Roldao et al. 2018; Tiefenbacher and Vivona 2018) focus on diverse minority groups and, by insisting on different dimensions of injustice that affect these groups, they consider the role of education in the development of individual capabilities in their relational aspect.

Drawing on the discourse analysis provided in the country cases, the analysis here contemplates the inclusionary and exclusionary aspects of education with respect to position of the minorities and vulnerable groups in different country contexts. The study has a comparative perspective that sheds light on the problems of redistribution, recognition and representation in the field of education through the investigation of common and divergent themes discussed in the country contexts.

\subsection{DISCOURSES ON EDUCATION IN SIX COUNTRY CONTEXTS}

Drawing on the country cases studied within the framework of the ETHOS project, ${ }^{3}$ problems regarding access to good quality education are observed to be related to the 'segregated' character of the education system, with inequalities of access to education closely reflecting the spatial dimension of inequality. The country studies demonstrate that the quality of schools differs according to the characteristics of the neighbourhoods divided along the intersecting lines of class and ethnicity. Socio-economic differences, that is, redistributive factors, remain important in identifying the inequalities and vulnerabilities which affect the religious and ethnic minorities in the European context.

Education systems often tend to be 'difference blind' or differences are addressed in a discriminatory manner by using the language of 'disadvantage' (see Kende 2018; Roldao et al. 2018). While difference blindness operates as a barrier to the acknowledgement of the claims and grievances, recognition 
of difference which takes the form of misrecognition informs policies that lead to further segregation. The questions of 'managing diversity' in contrast to 'difference blindness' also relate to the question of the accommodation of different values/value systems in the education system (Dupont 2018). The exclusionary dynamics often operate through the feelings of alienation of the students from minority groups whose history, culture or language do not find a place in the curriculum or appear in a negative light. Their values are interpreted to be in conflict with the way society's values are defined, their claims for cultural recognition are seen as a threat to social cohesion (Dupont 2018). Their access to channels of representation is often limited and they do not have the opportunity to adequately express their grievances and claims and to contest stereotyping and stigmatizing tendencies concerning their values or their cultural worth. Equal participation, trust and representation are significant concepts to understand education's role in shaping the boundaries of a 'good' society. If the value universes are seen to have incompatible characteristics reflecting different conceptualizations of good life, the transmission of culture would appear as a particularly difficult problem to be solved by balancing the demands of the family and the society.

\subsection{1 'Managing' Diversity}

The educational discourses that are revealed address several tensions and controversies around the accommodation of differences in the education systems. In some cases, difference blindness has been brought forward as a way to tackle ethnicity-based discrimination as in Portugal (Roldao et al. 2018). The absence of statistical data on ethnicity and race is stated as an indication of the tendency to overlook a crucial aspect of the injustices faced by vulnerable groups. This tendency is reflected in the official discourses which prioritize poverty as the main factor behind the inequalities in access to education and overlook the barriers constituted by ethnic and racial identity (Roldao et al. 2018).

Where the disadvantages are dissociated from the underlying social and cultural inequalities, the recognition of disadvantage might easily articulate with discriminatory tendencies. In Hungary, this problem is presented regarding 'the double discourse' which denotes the use of 'disadvantaged children' and 'Roma children' as synonyms (Kende 2018). As an aspect of the 'colour-blind racism' in the Hungarian education system where the ethnic registration of Roma children is prohibited, the terms 'disadvantaged' or 'multiple disadvantaged' are used when what is meant is the Roma students: 'Since the Roma is not just a social category but also a recognized minority with specific rights deserving recognition ..., using the 'disadvantaged' category makes the Roma children as an ethnic minority disappear from the system' (Kende 2018, p. 24). 
The recognition of Roma in association with their disadvantages is a tendency that can be observed in different country contexts. It reflects and reinforces the prejudices underlying the discrimination faced by the community. Different policy measures introduced to address the observed disadvantages often contribute more to segregation than the inclusiveness of the education system. This is also the case in Turkey as an interviewee who is a Roma activist observes:

Teachers often label Roma children as children having difficulties in learning and there are cases that Roma children are sent to CRCs (schools for students with special needs). If the CRCs diagnose these children as mentally disabled, this will have serious consequences for their future life course. (Akkan and Ruben 2018, p. 20)

The problems of stigmatization and discrimination of minorities recognized by their disadvantages manifest themselves also in the Austrian context where the deficiency in German language aptitude appears as a central issue in the debates on inclusive education (Tiefenbacher and Vivona 2018). The measures taken to deal with German language deficiency, which include the separation of 'irregular' students with a migration background lacking language skills from the 'regular' ones have implications on the irregular students' future prospects in education (Tiefenbacher and Vivona 2018).

In Austria, where the question of diversity is mainly discussed in relation to native language differences and the imperfect mastery of German as a key element shaping the problems of equal access to education, Tiefenbacher and Vivona (2018) reveal that the children from families with a migration background are the targets of such arrangements. The discourses draw attention to the possibility that in the presence of a 'deficiency-oriented' approach, discriminatory tendencies can play a role in reducing differences to a real or assumed disadvantage.

Discourses on diversity and the policies designed to deal with social segregation vary according to the perceptions of the reality of class-related, ethnic, religious or racial differences which are also time and space bound. As elaborated by Dupont (2018), in the UK acknowledgement of cultural diversity appears as a new phenomenon, a reality of 'modern' British society that is 'increasingly' becoming 'multi-faith', 'multicultural', 'diverse', 'pluralist' or of 'mixed-belief' (Dupont 2018, p. 14). 'The irreversible plural nature of modern Britain' is a challenge that must be faced with an adequate response to avoid 'the conflict that can and does take place among those of different cultures and beliefs' (Dupont 2018, p. 14). Diversity is approached as a problem to be managed and calls for a system of education which helps the children to learn to 'navigate' the rough sea of cultural diversity (Dupont 
2018). The approach to diversity as a problem to be managed is also prevalent in other country cases. In the Netherlands, for example, civic education was introduced in 2006 and currently there is a legislative proposal to make civic education mandatory in all schools, including denominational schools. These steps are taken also with the objective of providing students with an education on citizenship and democratic rule of law, with the intention of contributing to social integration in a society of diverse cultures with different value systems (Hiah 2018).

In Portugal, the 'management of diversity' that goes against the denial of difference appears as a recent concern reflected in 'the creation of some institutions and projects, and even some alterations in the legislation' (Roldao et al. 2018, p. 20). Such developments reflect a new perspective on diversity that challenges the discourses on the 'non-racial' nature of Portuguese colonialism and the unproblematic character of Portugal's multicultural society (Roldao et al. 2018).

In the case of the current Hungarian government's approach to the problems of equal access to education encountered by the Roma minority, the term segregation does not have entirely negative connotations. As Kende (2018) demonstrates, the inclusion of Roma in the Hungarian public education system is emphasized as a major goal in the National Social Inclusion Strategy 2011-2020. However, in the official government discourses, segregation at school is put forward as an inclusionary mechanism for Roma students to catch up with the larger society which is referred to as 'affectionate segregation' (Kende 2018, p. 28). The segregation that is implemented is out of compassion towards Roma students left behind. Thus, the changes in the regulations and the application of the legal prohibition on segregation could easily be argued to have an exclusionary impact on the Roma minority. The policy of integration through 'affectionate segregation' could be welcomed by the 'white' majority who are happy to provide a good education for their children by separating them from the Roma children.

\subsubsection{Values and Cultural Worth}

The recognition of group difference appears in conflicting discourses on the 'respect for cultural and religious sensitivities' on the one hand and the possible tension between the values of the society and those of minority groups on the other. In the UK and the Netherlands, respectively, 'Britishness' and 'Dutchness' are discussed as the values of the larger society that should be embraced by the minority. In this regard, Dupont (2018) refers to the policy 
document Green Paper (2018) which emphasizes the importance of acquiring British values in education:

Children and young people should be taught about fundamental British values and should have the opportunity within school, further education, and beyond the school gates to mix and form lasting relationships with others from different ethnic, religious or socio-economic groups so they are well equipped for adult life. (Dupont 2018, p. 44)

In parallel to this emphasis of 'Britishness', Dupont draws attention to discourses where the 'overemphasised Muslimness at the expense of Britishness' is problematized and 'what it means to be British Muslim in contemporary society' (Dupont 2018, p. 25) is questioned.

As elaborated by Hiah (2018), in the Netherlands civic education is meant to enable the religious and cultural minorities to acquire the knowledge of the values of a larger society. A recent legislative proposal underway is described which aims to enforce civic education defined in terms of learning about 'Dutchness' in all schools:

Dutch traditions, values, and freedoms must be anchored in education. It is expected from the teachers to endorse Dutch values and freedoms. Every teacher needs to know how to communicate these values to their students. In this way, students become better acquainted with Dutch fundamental rights, values, and traditions and learn how we treat each other in the Netherlands. (Hiah 2018, p. 12)

In Turkey, the cultural construction of Turkishness has been problematized by the Alevi community that is not able to identify with this construction. As discussed in the Alevi Democratic Opening Report:

The state since the founding years of the Republic has constructed the Turkish identity on several dimensions and legitimized it. Ethnic, religious, and cultural dimensions that come together and forms this identity are Turkishness, Muslimness, intertwined with modern life in society. (T.C. Devlet Bakanlığ 2010 , p. 145)

The discourses on the embracement of larger values of the society also recall the contested nature of cultural worth of different religions, ethnicities or belief systems. Dupont (2018) points to the hierarchies in value discourses in the UK where Islamic values are situated at a lower level due to the perceptions of their 'oppressive' nature as a Muslim activist interviewee observes:

Religion is hierarchised in the UK. I feel like the way that we look at organised religion is very much - it correlates or it's very similar to the understanding of superiority and white supremacy. So I would say there are certain religions like, well, Christianity that are seen very differently and are perceived very differently to Islam. I would say something about Hinduism and Sikhism as well in the sense that 
Hinduism, Sikhism - at the moment Hindus are seen as the community to model the rest of minority communities on. They're seen as being 'integrated'. They've made it. While the Muslim community, it's not seen that way. We're going back to this kind of idea of the clash of civilisations and the barbaric, very oppressive religious doctrine Islam has, and then the more liberal or progressive, like maybe acceptance of sexualities - people are picking and choosing. And that difference is being negatively constructed in a way that is in favour of certain religions and not others. (Dupont 2018, p. 51)

The tendency to identify ethnic differences with disadvantage, which is particularly strong in the case of Roma, is also closely related to perceptions on values. In Hungarian and Turkish discourses, the Roma community is depicted as one that does not comply with middle-class values. Kende explains that in Hungary: 'The quantity of the curriculum for this very low socialized group is so incomprehensible and because the curriculum is also lexical knowledge-based that schools cannot be a pleasant experience for them' (Kende 2018, p. 32).

In parallel to the discourses on minority values and their compatibility with the values of the larger society entrenched in the education system, another issue is the extent to which minority cultures are included in the school curriculum. The absence of the history and culture of minorities is problematized in the narratives in different countries as a reflection of difference blindness or misrecognition. Akkan and Ruben (2018) signal non-recognition and misrecognition of Alevi in the Turkish curriculum and in the UK, the Netherlands and Portugal the silence of the curriculum on the colonial past emerges as an issue that determines the belonging of the minorities to the country. Hiah critically argues that 'the diversity in the stories' is not being reflected in the curriculum and such curriculum lacks 'attention for the migration history of the Netherlands including the Dutch colonial past and the role of the Netherlands in the slave trade' (2018, p. 16). Another striking story in the Netherlands is the festivity of 'Sinterklaas' during which the mythical figure of Saint Nicolas is accompanied by his black-faced helpers - Black Petes. Regarded by the (white) majority as a harmless children's festival, it is seen by others to be inherently tied to the history of slavery; with the figure of Black Pete perceived as a caricature of black people. Hiah argues that 'the absence of quality education on the history of slavery and the colonial past has resulted in the misrecognition of minorities in Dutch society' (2018, p. 16).

Roldao et al. also draw attention to the inferior depiction or non-representation of minorities in the Portuguese history curriculum: 'A significant part of the Portuguese population is not represented in history books or, if they are, they are represented as inferior, not fully-citizens, and their history is not part of the national history. This is the case of afro-descendants and Roma communities' (Roldao et al. 2018, p. 18). Exploring this issue as a European problem, 
Roldao et al. (2018) critically argue that Europe is presented as a positive construction without any references to the colonial past. Dupont (2018) states that the UK discourses on the 'whiteness' of schooling reinforced by 'a specific blindness to global and migration issues' are illustrated by statements by a Muslim activist as well as by a non-Muslim teacher and a parent who mentioned that history classes focus on 'the Tudors and the Kings and the Queens': 'It was not about kind of like the British empire or imperialism or colonialism and how that has impacted and shaped the way that minority communities are seen in the UK today' (Dupont 2018, p. 30).

If children from minority groups are discriminated against, alienated or are overwhelmed by the subjects they are asked to master, that would obviously have a negative effect on their happiness and well-being. A school system where children do not feel they belong can indeed make children unhappy, and parents can respond to this by seeking separate niches in the education system which they think would serve the needs of their children and positively contribute to their happiness and well-being. However, the parents' choices are often informed by the desire to educate their children in accordance with their own values and their right to do so is rarely contested in most European contexts. Conflicts and controversies emerge when the right in question is expressed with references to the impact of education on identity formation and demands for an education which would foster the children's feelings of belonging in the cultural milieu of the family and close community.

Happiness and well-being are closely related to the feeling of belonging. If these value universes are seen to have incompatible characteristics reflecting different conceptualizations of good life, the transmission culture would appear as a particularly difficult problem to be solved by balancing the demands of the family and the society. The controversies around this problem are exacerbated by the tendency to identify identity and culture with religion, as extensively discussed by Dupont regarding the UK. He refers to the association British Muslims for Secular Democracy that denounces educators who 'have overemphasized Muslimness at the expense of Britishness and the whole child' (Dupont 2018, p. 26).

It is probably not possible to have exact prescriptions about the extent to which the existing rules can be bent or religious beliefs that seem to conflict with gender discrimination can be accommodated in practice without compromising the children's present well-being as well as their future choices about the life they wish to live. The controversies that emerge here are not necessarily between Muslims and non-Muslims but between people with different views about the values to be transmitted in education. There might be a way of addressing them without overlooking the underlying inequalities that affect the children's position in the education system in the present and the terms of their participation in society in the future. This would require reconsidering 
the existing rules and practices as well as the curriculum. The same observation can be made in relation to the controversies that are reflected in different discourses on the problems of and expectations from education in different country contexts.

\subsubsection{Social Cohesion, Trust and Representation}

The relationship between social cohesion and an inclusive system of education is a two-way one. Different dimensions of injustice that are highlighted in different discourses on education constitute an obstacle against the positive contribution education is expected to make to social cohesion. At the same time, in the societies divided along the lines of class, ethnicity, religion or race, the inequalities that characterize social relations define the exclusionary dynamics observed in the realm of education.

The inability to develop a sense of belonging in society because of the character of the curriculum or the experiences of discrimination in school leads to feelings of alienation and the erosion of trust in the system of education as well as in the society at large. This is forcefully stated by the representative of an anti-racist association in Portugal:

Minorities often have a relationship of fear with the State and the school is an institution of the State; then they also end up delaying their children's enrolment in school, and, especially, they do not create a relationship of trust. The school has to be concerned about building trust. (Roldao et al. 2018, p. 13)

Where there is an erosion of trust emerging from the exclusionary effect of the curriculum as well as the rules and practices, parents who feel powerless to make their grievances heard might also contribute to enhanced school segregation by the choices they make in relation to the education of their children. A Roma activist in Hungary interviewed by Kende refers to this by saying that

The [Roma] parents themselves cannot be convinced to send their children to mixed schools, primarily because they cannot afford the cost of the public transport. Secondly, they feel more secure in the nearby segregated schools, and thirdly they are afraid that their children are not able to cope with the higher expectations. (Kende 2018, p. 34)

Given the inequalities of 'voice' which block the representation of minority grievances and claims, the minorities might believe that they do not have the possibility to question and contest the prevailing social institutions and practices. They might therefore accept and adapt to them in whatever way they find to protect the well-being of their children. Roldao et al. (2018) observe that some of the attempts that are made to include minority representation in 
Portugal mainly aim at facilitating the management of ethno-racial diversity in the realm of education. This is reflected in the following quotation from the representative of the High Commission on Migration:

The representativeness of all the interlocutors is absolutely decisive for the success in the implementation of public policies. In this way, all mechanisms of hearing and participation must be stimulated in its various aspects: from more formal mechanisms to informal structures such as youth groups or Neighbourhood Associations. It is also necessary to ensure that the presence of more established structures, such as the Migrant Associations, continues to function, promoting, inter alia, the dissemination of training opportunities and funding lines for projects on the ground. (Roldao et al. 2018, p. 23)

This particular perspective on representation is problematized because it does not involve any concern for the presence of minorities in leading places in policymaking even in the areas which concern them directly. Minority representation is thus seen in relation to their role as mediators, consultants or facilitators in policy processes.

In Austria, there is a well-developed institutional frame for representation, but as one interviewee observed, the demands put forward by the unions of parents and students were not heard until recently. According to this interviewee, on the other hand, there have been important improvements recently and the impact of unions has increased (Tiefenbacher and Vivona 2018). What is worth noting in this assessment of the positive developments in representation is the emphasis of their 'newness' and their relationship with the approach adopted by the Ministry of Education and the Minister in person in Austria. This draws attention to the importance of the outlook of the ruling government and hence of the political environment in which the possibility of representation of different actors is defined. While there might be steps taken to allow a larger diversity in the voices that are heard in debates around the system of education by the government in power, dialogue and mutual understanding can still be impaired by the political controversies and tensions which prevail at the level of society.

In Hungary and Turkey, two countries marked by intense political polarization, the political environment appears to be particularly inimical to the expression of critical views in a healthy public debate. This is a point that receives particular emphasis in Hungary. Kende argues that 'there is no visible public debate about the role of education. In Hungary, every social issue is over-politicized and highly divisive among the left and the right, the liberal and conservative camps, without any interaction between the two sides' (2018, p. 31). Akkan and Ruben (2018) express similar concerns with respect to the silenced demands of the Turkish secular middle class. Secular groups confront the government regarding its policies of Islamization in education through the 
proliferation of religious schools and the introduction of elective courses on religion in the curriculum. They point to the parents' organization advocacy work and the difficulties it faces in a political environment where the Ministry of Education refuses to accept secular groups as partners and easily disregards their claims (Akkan and Ruben 2018).

The fact that in different contexts diversity is frequently mentioned as a problem to be managed and dealt with also makes it difficult to discuss the role of education in contributing to social cohesion in a healthy environment of dialogue with equal representation. In the case of the Muslim minority in the UK, Muslim schools are central to the debates around the 'balkanization' of the education system which is an emphasized factor in the failure of education to contribute to social cohesion. Thus, making the school system reflect the diversity in the society appears to be a widely shared objective. However, controversies around this objective could be hardly avoided given the complex problems posed by different perspectives on religion and secularism which articulate with security concerns. In relation to 'non-discrimination' as a principle, for example, non-Muslim stakeholders portray Islamic extremism as a problem, while it is the problematization of Islam itself that attracts the criticism of Muslims (Dupont 2018). In some discourses on the problem of segregation in the UK, minority religious schools, Muslim ones, in particular, are seen as posing a particular challenge for social cohesion.

\subsection{CONCLUSION}

Based on the discourse analysis of six country cases, this chapter reveals that different dimensions of injustices, which are reflected in various forms of exclusion, define the position of the students from minorities and vulnerable groups in the system of education and thus constitute a barrier to the development of their capabilities. Discourses outline diversity as 'a problem to be managed'. Injustices related to recognition, which constitute an important factor defining the inequalities in education, pertain to the problems of 'difference blindness' and 'misrecognition', as well as the third problem which cannot be separated from the first two, pertaining to 'the attitudes towards the worth of different cultures'.

Socio-economic inequalities and cultural differences which are not adequately addressed define the limitations of education in meeting the expectations about capability development. They also create doubts about the contribution of education to social cohesion. The combined effect of injustices related to redistribution and recognition make the minorities feel discriminated against, alienated or excluded, and consequently lead to an erosion of trust in society. Their access to channels of representation is often limited and they do not have the opportunity to adequately express their grievances and claims and 
to contest stereotyping and stigmatizing tendencies about their values or their culture. Apart from the preconceptions about values and culture (of both the minorities and the society) which often inform the approaches to social cohesion, the perceptions of culture and identity as fixed and unchanging might not serve the development of capabilities as the core objective of education. The parents' freedom of choosing the type of education which they find in conformity with the values underlying their conception of good life might not be in conformity with the children's freedom to choose and affect their life chances. There is, therefore, a need to question the given views on values, cultures and conceptions of good life in a transformative approach that addresses the underlying injustices that lead to capability deprivation.

\section{NOTES}

1. Sen (2000). See also Fraser (2001, p. 29) where she contemplates the institutionalized value patterns that deny some people the status of full partners in interaction - whether by burdening them with excessive ascribed 'difference' or by failing to acknowledge their distinctiveness.

2. https://www.un.org/en/universal-declaration-human-rights/ (accessed 19 August 2020).

3. https://ethos-europe.eu (accessed 19 August 2020).

\section{REFERENCES}

Akkan, Başak and Duygun Ruben (2018), 'Discourses on minorities' (and vulnerable groups) access to education: Alevi and Roma Case', country report for ETHOS report D4.3 (unpublished).

Dupont, Pier-Luc (2018), 'Political discourses on educational justice and Muslims in the UK', country report for ETHOS report D4.3 (unpublished).

Fraser, Nancy (2001), 'Recognition without ethics?', Theory, Culture and Society, 18 (2-3), 21-42.

Fraser, Nancy (2003), 'Social justice in the age of identity politics: Redistribution, recognition, and participation', in Nancy Fraser and Axel Honneth (eds), Redistribution or Recognition: A Political-Philosophical Exchange, London: Verso, pp. 7-109.

Fraser, Nancy (2008), 'From redistribution to recognition? Dilemmas of justice in a post-socialist age', in Kevin Olson (ed.), Adding Insult to Injury, London: Verso, pp. 11-41.

Gewirtz, Sharon (2006), 'Towards a contextualized analysis of social justice in education', Education Philosophy and Theory, 38 (1), 69-81.

Hiah, Jing (2018), 'National discourses about minority social rights with respect to access to education', country report for ETHOS report D4.3 (unpublished).

Huttunen, Rauno (2007), 'Critical adult education and the political-philosophical debate between Nancy Fraser and Axel Honneth', Educational Theory, 57 (4), 423-33.

Keddie, Amanda (2012a), Educating for Diversity and Social Justice, New York: Routledge. 
Keddie, Amanda (2012b), 'Schooling and social justice through the lenses of Nancy Fraser', Critical Studies in Education, 53 (3), 263-79.

Kende, Agnes (2018), 'Discourses on Roma students' access to education: Inclusionary and exclusionary aspects', country report for ETHOS report D4.3 (unpublished).

Lister, Ruth (2003), Citizenship: Feminist Perspectives, New York: Palgrave Macmillan.

Lynch, Kathleen and John Baker (2005), 'Equality in education: An equality of condition perspective', School Field, 3 (2), 131-64.

Nussbaum, Martha (2000), Women and Human Development, Cambridge: Cambridge University Press.

Power, Sally (2012), 'From redistribution to recognition to representation: Social injustice and the changing politics of education', Globalization, Societies and Education, 10 (4), 473-92.

Roldao Cristina, Bruno Sena Martins and Maria Paula Meneses (2018), 'Political and advocacy discourse analysis of inclusionary and exclusionary aspects of education', country report for ETHOS report D4.3 (unpublished).

Salát, Orsolya (2019), 'Comparative report on the right to education: An assessment of the legal framework of six countries from the perspective of recognitive and redistributive justice', ETHOS report D3.6, accessed 19 August 2020 at https://ethos -europe.eu/.

Sen, Amartya (1992), Inequality Re-examined, Oxford: Oxford University Press.

Sen, Amartya (1999), Development as Freedom, New York: Alfred A. Knopf.

Sen, Amartya (2000), 'Social exclusion: Concept application and scrutiny', Social Development Papers No.1, Asian Development Bank, accessed 3 April 2020 at https://www.adb.org/sites/default/files/publication/29778/social-exclusion.pdf.

Sen, Amartya (2009), The Idea of Justice, Cambridge, MA: Harvard University Press.

T.C. Devlet Bakanlığı (2010), 'Alevi Çalıştayları Nihai Raporu', Ankara 2010, accessed 9 April 2020 at https://www.hyd.org.tr/attachments/article/633/rapor-alevi -calistaylari-nihai-raporu.pdf.

Tiefenbacher, Wanda and Maddalena Vivona (2018), 'Minorities and access to education in Austria', country report for ETHOS report D4.3 (unpublished).

Tikly, Leon and Angeline M. Barrett (2011), 'Social justice, capabilities and the quality of education in low income countries', International Journal of Education Development, 31 (1), 3-14.

Unterhalter, Elaine (2003), 'The Capabilities Approach and gendered education', Theory and Research in Education, 1 (1), 7-22.

Walker, Melanie (2006), 'Towards a capability-based theory of social justice for education policy-making', Journal of Education Policy, 21 (2), 163-85.

Walker, Melanie and Elaine Unterhalter (2007), Amartya Sen's Capability Approach and Social Justice in Education, New York: Palgrave Macmillan. 